\title{
Ginástica artística competitiva e a filosofia dos técnicos
}

\author{
Myrian Nunomura $^{1}$ \\ Mauricio Santos Oliveira ${ }^{1}$ \\ Odilon José Roble ${ }^{2}$ \\ Michele Carbinatto ${ }^{3}$ \\ ${ }^{1}$ Escola de Educação Física e Esporte de Ribeirão Preto, Universidade de São Paulo, SP, Brasil \\ ${ }^{2}$ Faculdade de Educação Física, Universidade Estadual de Campinas, SP, Brasil \\ ${ }^{3}$ Departamento de Ciências do Esporte, \\ Universidade Federal do Triangulo Mineiro, Uberaba, MG, Brasil
}

\begin{abstract}
Resumo: O presente estudo é um recorte do projeto original intitulado "Diagnóstico do Processo de Formação Esportiva da Ginástica Artística no Brasil". Um dos temas de análise foi a filosofia de trabalho dos técnicos que atuam nas categorias de base e preparam os potenciais ginastas para as seleções nacionais. Entrevistamos 46 técnicos de 29 instituições esportivas do Brasil. Para a coleta dos dados utilizamos a entrevista semiestruturada e, para o tratamento dos dados, a análise de conteúdo proposta por Bardin (2010). Constatamos que a base filosófica ainda é inconsistente e que, em muitas instituições, esta se confunde com os próprios objetivos do programa de treinamento ou simplesmente inexiste. $\mathrm{O}$ fato merece considerações e criticas, mas sabemos que a filosofia não é desenvolvida durante os cursos de formação dos técnicos.
\end{abstract}

Palavras-chave: Ética. Instrução esportiva. Formação de atletas.

\section{Competitive artistic gymnastics and coaches' philosophy}

\begin{abstract}
The current study is a piece from the original project entitled "Diagnosis of the Artistic Gymnastics Development Program in Brazil". Among others issues, the coaching philosophy of coaches who are developing gymnasts that may be representative of the national team was a matter of analysis. We interviewed 46 coaches from 29 sports institutions in Brazil. As data collection we used a semi-structured interview and for data treatment we adopted the content analysis method of Bardin (2010). We have found out that there is an inconsistent philosophical basis, and in many institutions this has been mixed up with the objectives of the training program or just doesn't exist. This fact needs consideration and criticism, but we know that the coaching philosophy is not developed during the coaching education courses.
\end{abstract}

Keywords: Ethics. Sports coaching. Athletes' development.

\section{Introdução}

O termo filosofia, ainda que se refira a uma área específica do saber, é empregado amplamente em diversos contextos. Como constatamos na leitura de Bornheim (2003), a atitude de filosofar está no centro de qualquer uso que se faça da palavra filosofia. Assim, para que caracterizemos, por exemplo, a chamada "filosofia de vida", ou a "filosofia de trabalho" ou ainda, no nosso caso, a "filosofia dos técnicos de Ginástica Artística", é fundamental que entendamos como eles "filosofam". Filosofar, mais do que um sinônimo para "pensar" ou "abstrair", refere-se a uma mobilização ampla da capacidade intelectiva do sujeito pensante, na qual se articulam memórias, percepções e imaginações.
Desse modo, o sujeito filosofa na medida em que elabora uma razão para sua própria vida, para os valores que o cercam e para o conjunto amplo das relações sociais que estabelece com os outros sujeitos. E, do cotidiano dessas relações emergem razões de ordem prática para a vida, as quais farão parte do domínio ético. Por essa razão é que a ética pode ser compreendida como um campo do saber filosófico.

O ethos, palavra grega que está na origem do conceito de ética, é traduzida como "conduta", de tal modo que a ética, de modo geral, trata da arte da conduta, ou seja, de uma razão prática que orienta comportamentos e ações em torno da harmonia da vida coletiva, ou como cita ComteSponville (2003, p. 220), "a ética é um trabalho, 
um processo, um caminhar: é o caminho pensado de viver". Percebemos, portanto, como a ética é um exercício filosófico, pois se apresenta como "o caminho pensado de viver".

No Esporte, como atividade racional em busca de resultados bastante específicos, sejam eles relacionados ao lazer, à qualidade de vida ou ao rendimento esportivo, o papel do técnico é filosófico na medida em que articula interesses, organiza ações e lida com condutas e valores. Ainda que possamos supor que nem todos os técnicos esportivos reconheçam seu papel ético e filosófico, tais dimensões estão contidas inexoravelmente em suas ações e no cotidiano esportivo. Em outras palavras, podemos inferir que as atitudes dos técnicos, assim como suas ideias e valores, compõem um referencial ético e filosófico que recaem sobre a prática esportiva e que podem ser objeto de análise, tal como nos propomos nesse artigo.

Para sermos capazes de tal emersão e nos mantermos nos limites de nossa intervenção, entrevistamos 46 técnicos de GA que estão distribuídos em 29 instituições esportivas no estado de São Paulo e nas cidades de Curitiba, Rio de Janeiro e Porto Alegre. Elegemos a Análise de Conteúdo, tal como proposta por Bardin (2010), como procedimento metodológico para organização e tratamento dos dados. Esta proposta faz, ao mesmo tempo, uso da inferência e de uma forma de hermenêutica na qual os discursos dos sujeitos, no nosso caso os técnicos, são respeitados em sua inteligibilidade própria e a partir do qual não se busca relação com categorias extrínsecas, mas a logicidade inerente ao discurso. Espera-se assim que a filosofia dos técnicos surja como um dado razoavelmente compreensível e descritível.

\section{Esporte contemporâneo e a filosofia na instrução esportiva}

Segundo Haines (1989) é difícil definir o significado do Esporte e os motivos que levam as pessoas à prática esportiva, pois os adeptos e as modalidades são particulares e as razões da participação são diversas.

A autora ressalta a mudança de valores na sociedade nas últimas décadas. Nos anos 50, por exemplo, havia grande ênfase sobre a disciplina, a obediência, a subordinação e o "ajustamento ao molde". Atualmente, as pessoas estão mais preocupadas com o prazer, a vida agradável e a valorização da independência, da criatividade e dos sentimentos de autoestima e de auto identidade. Os indivíduos são encorajados a alcançar a excelência nas suas realizações, em todos os âmbitos da vida. E, essas mudanças refletiram, sensivelmente, sobre o sistema esportivo.

Sabemos que a formação esportiva é um processo que envolve inúmeras decisões, mudanças constantes, integração do conhecimento de áreas distintas, entre outros aspectos. Mas, a essência de todo programa esportivo deve estar centrada no desenvolvimento e na formação do ser humano, independentemente de seu talento e objetivo no Esporte.

Compete ao técnico auxiliar os seus atletas a alcançarem as suas metas no Esporte através de uma experiência positiva. Kidman e Hanrahan (2004) afirmam que as decisões e o comportamento dos treinadores é que determinarão se essa experiência proporcionará o sentimento de satisfação ou frustração ou, ainda, de sucesso ou de fracasso independentemente dos resultados.

Podemos dizer que são as ações e as atitudes dos técnicos que determinam o caminho que será seguido no processo de treinamento. E, segundo Kidman e Hanrahan (2004), estas refletem as suas crenças pessoais, valores, princípios e prioridades que são as bases do seu comportamento e que fundamentam a sua filosofia de trabalho.

A filosofia do técnico, ou do coaching que seria como o técnico instrui seus atletas, pode ser definida como um conjunto de valores e comportamentos que serve de guia para as suas ações como treinador (WILCOX; TRUDEL, 1998).

Martens $(\underline{1987}, \underline{2004})$ considera que a filosofia que apoia a atuação do técnico é influenciada, tanto pela sua filosofia de vida, como pela filosofia do próprio Esporte. Conforme Taylor e Wilson (2005), cada modalidade demanda características específicas do técnico, do atleta e do relacionamento entre os envolvidos.

Haines (1989) ressalta a importância de uma base filosófica bem consistente no programa esportivo, pois a filosofia norteia os objetivos gerais $\mathrm{e}$ as metas durante $\mathrm{o}$ processo de treinamento em longo prazo com vistas ao alto rendimento. 
Martens (2004) acredita que uma filosofia bem desenvolvida permitirá ao técnico atingir o sucesso ao atender, com mais eficiência, às demandas do esporte. Como os princípios e os valores que fundamentam as suas ações estão estabelecidos na filosofia, o autor considera que esta será muito mais importante do que o conhecimento esportivo para manter o técnico direcionado no processo de orientação dos atletas.

Além disso, a filosofia de trabalho permite que tanto o técnico quanto os atletas possam desenvolver um modo de pensar e atuar consistente e coerente (CASSIDY; JONES; POTRAC, 2004). Kidman e Hanrahan (2004) citam que todos os envolvidos devem conhecer a filosofia de trabalho do técnico, pois, desta forma, todos estarão comprometidos e os problemas com relação à falta de entendimento, falsas expectativas ou ausência de confiança podem ser minimizados. De acordo com Baker (1999) apud Lumpkin e Cuneen (2001), a integridade na orientação esportiva deve incluir essa articulação clara e a promulgação da filosofia.

É importante considerar, também, que as instituições e os programas variam na sua concepção filosófica, nos valores, no planejamento, no sucesso da instrumentalização, na criatividade e na capacidade em modificar e transformar. Cassidy, Jones e Potrac (2004) corroboram com essa afirmação e ressaltam que o caráter particular da organização esportiva ou do clube ao qual pertence o técnico exerce grande influência na sua filosofia de trabalho.

Lyle (1999) chama a atenção para os conflitos que podem ser desencadeados devido às diferenças de credo, valores e forma de atuação entre os indivíduos envolvidos no processo de treinamento. A pressão por resultados $e$ as expectativas dos atletas também foram relacionadas como fatores que influenciam o comportamento do treinador e, consequentemente, a sua filosofia de trabalho. McCallister, Blinde e Weiss (2000) citam a influência da pressão que os pais exercem sobre os técnicos e que, muitas vezes, contrapõem-se aos objetivos da participação dos jovens no esporte. De acordo com os autores, muitos pais enfatizam a vitória em detrimento da aprendizagem e da formação de seus filhos. Por fim, os autores apontam para a influência do próprio modelo esportivo moderno que promove a "vitória" e "ser o melhor".

Haines (1989) considera que a educação e a formação profissional do técnico também exercem grande influência na sua filosofia de trabalho, e que não se restringe apenas aos aspectos culturais e seus preceitos e valores pessoais, cuja opinião é corroborada por Reynolds (2005).

A busca pela excelência no esporte tem levado muitos técnicos e atletas a utilizarem formas antiéticas, seja para superar marcas ou vencer o oponente. Esta situação preocupa, sobremaneira, os educadores que debatem sobre os rumos do esporte (SEKINE; HATA, 2004).

Lumpkin e Cuneen (2001) criticam o esporte contemporâneo e afirmam que o sistema está repleto de indivíduos que parecem ter perdido o sentido do valor humano, o respeito por outros e o significado de flair play. Os comportamentos antiéticos não se esgotam nos relacionamentos interpessoais existentes no esporte ou nas atitudes antidesportivas que ocorrem nas quadras, campos ou piscinas, mas abrangem outros aspectos como o uso de drogas e o processo de recrutamento. Suspensões por violência, zombaria, pancadarias, agressões são situações comuns no Esporte atual.

Alguns técnicos e atletas justificam que esses comportamentos são estratégias necessárias para manter os financiamentos e patrocínios, para ganhar reconhecimento e recompensas e, principalmente, para vencer. Assim, esses e outros motivos contribuem para que a abordagem do esporte passe a ser "ganhar a todo custo", independente do nível de prática, e que se distanciam cada vez mais de uma abordagem humanista e educacional.

Lumpkin e Cuneen (2001) citam outros autores que concordam com a ideia de que os benefícios da prática esportiva como ensinar valores positivos, condutas éticas e autodisciplina seja um mito. Os autores relatam, também, que quanto mais tempo os indivíduos se envolvem no esporte competitivo, mais seus valores morais e comportamentos éticos enfraquecem. Os atletas são condicionados a aceitar o fato de que burlar regras para obter vantagens é plausível, pois, os comportamentos desviantes, por muitas vezes, não serão punidos. 
O que os técnicos e atletas não reconhecem é que a maneira como eles lidam com a violência, 0 racismo e a discriminação no esporte refletem os seus princípios e valores pessoais que estão diretamente ligados a sua filosofia de vida e, no caso dos técnicos, a sua filosofia de trabalho.

Podemos concluir que alguns técnicos e atletas valorizam o fair play de acordo com as regras do jogo, outros acreditam que vencer a todo custo é mais importante. Por isso, torna-se necessário que os envolvidos estejam cientes da filosofia de trabalho do técnico, da organização esportiva e do esporte em si para que os conflitos de interesse sejam minimizados entre as partes.

Consideramos ser crucial que os técnicos questionem os seus objetivos e a si próprio antes de estabelecerem sua filosofia de trabalho, pois, conforme Martens (2004), o desenvolvimento de uma filosofia consistente depende, em grande medida, do autoconhecimento do técnico e dos seus objetivos no esporte. Ele deve conhecer a si para poder auxiliar os seus atletas a se autoconhecerem e os objetivos serão responsáveis por modelar o seu comportamento.

Para iniciar um processo crítico e reflexivo com vistas ao desenvolvimento de uma filosofia de instrução esportiva, Lumpkin e Cuneen (2001) sugerem, em formato de questões, um autoquestionamento que contempla:

1) Em que se baseiam meus valores?

2) O que eu valorizo no esporte?

3) Eu valorizo as regras do esporte?

4) Como meus valores afetam os outros?

5) Quais valores são manifestados pelos outros no meu esporte?

Os autores não pretendem levantar um debate sobre o que seja certo ou errado, mas que cada um analise, criticamente, os seus valores e conheça a si próprio.

A importância desse autoconhecimento é reforçada por Reynolds (2005) que afirma que para desenvolver a filosofia de trabalho, o técnico deve se pautar no conhecimento de si, nos aspectos pessoais que necessita aprimorar e estar consciente dos seus princípios e dos obstáculos que enfrentará na carreira. Além do autoconhecimento, ele deve conhecer os seus atletas, seja a personalidade, as habilidades, as metas e os motivos pelos quais eles optaram em atuar no Esporte.
Em complementação a essas considerações supracitadas, Haines (1989) cita que o técnico deve analisar as tendências e os valores da sociedade; a filosofia da instituição a qual está vinculada; a sua filosofia pessoal; a qualidade do relacionamento entre ele e os seus atletas; as ações que os atletas realizarão; o seu estilo como técnico; e o ambiente social no qual ele está inserido.

Após essas reflexões, Lumpkin e Cuneen (2001) sugerem cinco passos para guiar o processo de desenvolvimento da filosofia pessoal, quais sejam:

(i) examinar as teorias filosóficas distintas que procuram oferecer fundamentos para compreender como cada pessoa define a verdade e como essa interpretação afeta seus valores no esporte.

(ii) estar atento para as metas que são mais importantes no esporte em relação aos resultados visados. Não somos lembrados apenas por nossas conquistas, mas, também, por nosso desempenho nos jogos.

(iii) conhecer os valores estabelecidos para o esporte, pois, independentemente dos valores individuais de cada um, alguns comportamentos serão admitidos, recompensados ou proibidos pelas organizações, patrocinadores e fãs. Cada pessoa deve refletir e decidir se cumprirá as regras ou se portará de maneira não ética.

(iv) determinar os comportamentos que 0 caracterizarão, pois o esporte oferece muitas oportunidades de demonstrar seus valores morais. Há inúmeras chances de decidir entre o bem e o mal, de demonstrar virtudes ou comportamentos imorais.

(v) estar seguro de que seus comportamentos são consistentes e concordantes com seus valores, pois, no esporte, há várias chances de demonstrar raciocínio moral maduro que conduzem às decisões éticas. As tentações para atuar de forma não ética podem ser superadas através da certeza de que a transgressão às regras será punida e que aqueles que agem conforme 0 espírito das regras será recompensado.

As pessoas envolvidas no esporte estão no centro das atenções, ou seja, seus comportamentos estão em evidência. Em especial, no alto nível do esporte, atletas e técnicos são vistos como modelos, os quais, 
baseados em seus comportamentos, poderão ser idolatrados ou ridicularizados.

De acordo com McCallister, Blinde e Weiss (2000), há aproximadamente 35 milhões de crianças e jovens entre seis e 16 anos de idade que estão envolvidas em atividades esportivas. $O$ fato mostra, sem dúvida, que o esporte tem papel proeminente na infância e na adolescência que são períodos críticos para o aprendizado de valores, princípios e habilidades que fornecem a base para a vida adulta. Assim, a participação de crianças e de jovens no esporte deve ser cuidadosamente monitorada.

Apesar do potencial de benefícios da prática esportiva, a participação no esporte pode resultar em estresse e tensão excessivos, nível baixo de raciocínio moral, ênfase na vitória, baixa autoestima, trapaceio, interiorização das normas de adultos, desconsideração do oponente e falta de respeito por outros.

A filosofia do técnico e sua habilidade em implementá-la é crucial e influencia o tipo de aprendizagem predominante no contexto esportivo. As crianças e os jovens aprendem muito no ambiente de convívio social e, em particular, a postura dos técnicos tem impacto expressivo sobre os valores e as habilidades para a vida futura dos praticantes. Assim, muito do que as crianças e os jovens aprendem depende do ambiente que o técnico constrói e de suas condutas. Segundo Sarmento (2005), o desenvolvimento humano é um processo decorrente da regulação entre o indivíduo e o ambiente. Os valores que animam nossos pensamentos e comportamentos emergem de situações concretas de um contexto e, somente a partir da análise deste contexto, em que estão inseridos os valores, é que podemos perceber como influenciar o processo de educação e de treino (ARAÚJO, 2005).

A natureza das interações entre técnicos e atletas e as características positivas/negativas dessas experiências também têm impacto sobre a possibilidade do indivíduo continuar seu envolvimento no esporte ou não.

O estudo conduzido por McCallister, Blinde e Weiss (2000), que envolveu 22 técnicos de baseball e softball, revelou que apesar destes terem consciência da importância do contexto educacional do esporte e do ensino de valores e de habilidades para a vida, a maioria não se sente preparada para estruturar um ambiente de ensino que favoreça esses resultados desejáveis. Surpreendentemente, alguns desses técnicos acreditam que esses valores e habilidades surgem automaticamente através da participação no esporte. Muitos dos comportamentos e das ações exibidos pelos técnicos são aqueles que não gostaríamos que fossem seguidos pelas crianças e jovens.

Outro ponto levantado foi a inconsistência entre a filosofia e o comportamento do técnico, pois este é, sem dúvidas, o melhor indicador da sua filosofia. Ademais, o estudo revelou que a grande maioria dos técnicos teve experiência no esporte organizado e que este passado esportivo o expôs a uma variedade de técnicos os quais influenciaram sua abordagem atual. Muitos técnicos afirmam serem extremamente competitivos, cuja qualidade eles citaram, repetidamente, como aquela aprendida através de sua vivência esportiva. As evidências comprovam o impacto dos técnicos sobre a formação dos atletas, sobretudo quando estes assumem futuramente posições na organização esportiva.

Muitos técnicos parecem bem intencionados sobre a qualidade da participação no esporte. Entretanto, muitas vezes, estes se deparam com a própria formação profissional insuficiente e/ou inadequada, com as experiências pouco construtivas e que não contribuíram para auxiliar a definir uma base filosófica consistente. Consequentemente, McCallister, Blinde e Weiss (2000) concluem que, para realçar os valores dos programas esportivos para os jovens, é preciso ter muita atenção para a seleção, monitoramento e desenvolvimento do profissional que atua, sobretudo, no esporte infantil e juvenil.

De acordo com Salgado (1999), o treinador precisa ter consciência do impacto de sua ação, tanto sobre a formação esportiva como na pessoal. Sabemos que a prática esportiva contribui para a formação social, pois ensina valores, normas e condutas perante outros, a compartilhar decisões, a liderar e ser liderado, a aceitação de si e do grupo, a aprender o valor do fracasso e da vitória, o espírito competitivo, o esportivismo e a autoconfiança, o respeito aos direitos e deveres, entre outros. Tais competências psicológicas e sociais contribuirão, também, para outros setores da vida. Mas, quando o esporte presta-se a satisfazer as ambições do treinador e não àquelas 
necessidades e interesses dos praticantes, todos esses atributos podem ter um viés negativo para a formação atlética e pessoal. Gonçalves (1999) aponta a importância de se adotar uma concepção filosófica e persistir nos seus valores e princípios através de uma conduta pedagógica apropriada e ética com vistas ao desenvolvimento dos praticantes.

\section{Procedimentos metodológicos}

Seguimos o caminho da pesquisa qualitativa para compreender o contexto da GA competitiva do Brasil, particularmente, identificar a filosofia de trabalho daqueles que vivem este cotidiano.

Para a coleta de dados, utilizamos a entrevista semiestruturada, pois esta valoriza a presença do investigador e oferece perspectivas para que os sujeitos alcancem a liberdade e a espontaneidade necessárias para 0 estudo, 0 que torna 0 processo de investigação enriquecedor (TRIVIÑOS 1987). Esta técnica permite que perguntas, previamente formuladas, no roteiro preestabelecido, possam ser substituídas dependendo dos resultados e das evidências que o pesquisador obtém ao longo do procedimento.

Consultamos as Federações para listar as entidades filiadas cujos ginastas participavam dos torneios oficiais estaduais e nacionais das categorias de base, a saber: pré-infantil, infantil, infanto-juvenil e juvenil.

A participação dos sujeitos foi de caráter espontâneo e todas as entrevistas foram realizadas no local de treinamento.

Visitamos 29 instituições esportivas do Estado de São Paulo e cidades do Rio de Janeiro, Curitiba e Porto Alegre, devido à representatividade numérica e qualitativa destas localidades no contexto nacional da GA. Entrevistamos 46 técnicos, sendo 34 do setor feminino e 12 do setor masculino. Apoiados em um roteiro, os técnicos foram entrevistados, individualmente, e seus depoimentos registrados em miniDV. Solicitamos que os técnicos reportassem sobre a base filosófica de seu trabalho.

Para o tratamento dos dados, optamos pela análise de conteúdo de Bardin (2010) que ocorreu em três etapas: pré-análise, exploração do material e a inferência.
Optamos pela diferenciação por gênero para posterior comparação devido à proximidade do conteúdo dos depoimentos. Não procedemos à distinção dos técnicos por categoria competitiva, pois, na maioria das instituições, estes são responsáveis por mais de uma categoria.

\section{Resultados e discussão}

\section{Categoria feminina}

Sobre a base filosófica dos técnicos, podemos observar uma concentração significativa dos depoimentos sobre a importância da educação geral do indivíduo, a busca pelo prazer, a satisfação pessoal e os fatores sócioafetivos que permeiam a prática no ginásio.

Podemos compreender que a atuação do técnico ultrapassa os limites do esporte e possui um papel importante na formação do indivíduo e na sua totalidade. Autores como Kidman e Hanrahan (2004) afirmam que os técnicos têm um grande impacto no desenvolvimento e nas vidas dos indivíduos sob sua orientação. Cogan e Vidmar (2000) acreditam que um técnico de GA não ensina apenas os aspectos relacionados à modalidade, mas, também, à vida.

Os técnicos mencionam, pontualmente, a formação pessoal, o desenvolvimento do respeito, da disciplina, da perseverança, da responsabilidade e de hábitos saudáveis, os quais eles acreditam que sejam importantes, não apenas no esporte, mas para a vida toda.

Na literatura, a função educativa é mencionada por Smoleuskiy e Gaverdouskiy (1996) cujo objetivo é desenvolver as capacidades dos esportistas, as qualidades volitivas e morais que, consequentemente, auxiliarão no aperfeiçoamento das intempéries individuais da personalidade. Segundo os autores, "la esencia pedagógica de la actividad de entrenador se manifiesta com claridad especial em el trabajo educativo, dirigido hacia la esfera moral de los alumnos" (p. 347-348).

O aprendizado, elencado pelos sujeitos, que ocorre através da experiência com as derrotas, os sacrifícios, as frustrações e os desafios vivenciados no cotidiano da GA contribuem para esta formação pessoal e são aspectos que

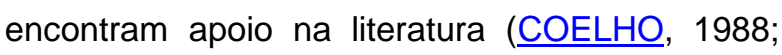
ARAÚJO, 2005). 
Tabela 1. Síntese dos resultados do setor feminino ${ }^{1}$.

\begin{tabular}{|c|c|c|}
\hline Categoria & Subcategoria & Unidades de registro \\
\hline \multirow[t]{2}{*}{ Educação } & $\begin{array}{l}\text { Formação } \\
\text { pessoal }\end{array}$ & $\begin{array}{l}\text { T3: "dar atenção maior explicar que elas são novas, que treinam a pouco tempo, que } \\
\text { enfrentam equipes mais experientes" } \\
\text { T4, T8, T10, T11, T12, T16, T18, T22: "disciplina" } \\
\text { T5, T7, T8, T15, T16, T17: "respeito..." } \\
\text { T13: "a preocupação maior é a formação delas como ser humano". T14: "Importante ela } \\
\text { participar e ver suas capacidades e dificuldades que vai encontrar ou não"; } \\
\text { T20: "sabem que vai competir com pessoas muito boas e saber se posicionar que a gente } \\
\text { vai ganhar e perder né, o que importa é fazer o melhor né”. } \\
\text { T22C: "você treinador deve saber quem é quem... e a competição pode ter coisas } \\
\text { positivas e tem também lado bem negativo". } \\
\text { T25: "se ela está insegura eu não exijo isso dela"; "eu valorizo o Eu". } \\
\text { T29C: "responsabilidade, maturidade, é superar desafios, né, fator psicológico é } \\
\text { extremamente trabalhado com elas...". }\end{array}$ \\
\hline & $\begin{array}{c}\text { Educação } \\
\text { formal }\end{array}$ & T8, T 20 : "a maioria sai daqui depois já como profissional, tendo um estudo" \\
\hline \multicolumn{2}{|c|}{$\begin{array}{l}\text { Prazer ou gosto pelo esporte, } \\
\text { satisfação pessoal }\end{array}$} & $\begin{array}{l}\text { T2, T3, T13, T 15, T18 : "isso tem que ser prazeroso para elas". } \\
\text { T6:" a participação... valorizo aquela q tem vontade". } \\
\text { T27: "pra satisfação pessoal, pra como esporte". } \\
\text { T29A: "aqui dentro somos completamente apaixonados por GO". }\end{array}$ \\
\hline \multicolumn{2}{|c|}{$\begin{array}{l}\text { Incentivo financeiro, } \\
\text { assistencialismo }\end{array}$} & $\begin{array}{l}\text { T2: "Eles (CBG) estão tentando segurar com dinheiro, alguma projeção [...]". } \\
\text { T10A: "Essa mudança financeira muda muito a perspectiva do atleta" } \\
\text { T11: "umas chegavam sem comer... a gente paga pessoa pra buscar na casa, almoçam } \\
\text { no ginásio, outras estudam aqui perto". } \\
\text { T22B: "Se tivesse recebendo, aí cobraria mais, mas como não, é preciso um diálogo..." }\end{array}$ \\
\hline \multicolumn{2}{|c|}{ Saúde, formação física } & $\begin{array}{l}\text { T8: "a Ginástica dá a nível de coordenação, todo o nível motor" } \\
\text { T13: "higiene, postura, e educação". } \\
\text { T27: "de fazer bem pro corpo, pra mente". }\end{array}$ \\
\hline \multicolumn{2}{|c|}{ Fatores sócio-afetivos } & $\begin{array}{l}\text { T2: "valorizo mais o vínculo, a amizade, o relacionamento, o social... acho isso aqui tão } \\
\text { importante quanto chegar aqui, treinar e ir embora". } \\
\text { T3, T 23, T 29A: "se unam, e tenham convivência. } \\
\text { T5, T 10, T 17: "companheirismo". } \\
\text { T6, T 11, T 24, T25: "mais amizade, grupo, sentir-se bem". }\end{array}$ \\
\hline \multicolumn{2}{|c|}{ Experiências anteriores } & $\begin{array}{l}\text { T2: "Eu trago o de bom para cá e o que foi ruim e que me fez crescer tambem, mas de } \\
\text { uma forma um pouco mais dosada." } \\
\text { T26: "cada um forma a sua... A sua cartilha..."; "A gente elimina o que é ruim, né?". }\end{array}$ \\
\hline
\end{tabular}

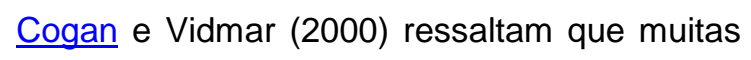
crianças, aspirantes à elite mundial da GA, deixam seus lares para treinar com técnicos renomados na esperança de obter grandes conquistas. Isso aumenta a influência dos treinadores no processo de formação desses jovens.

Muitos técnicos lidam com crianças provenientes de famílias menos favorecidas e, assim, citam a importância de tratar assuntos cotidianos no ginásio, tais como hábitos de higiene e de saúde.

Martens (2004) e Lyle (2002) destacam que os técnicos passam um longo período no ginásio interagindo com os seus atletas. Essa interação possibilita uma dinâmica entre as características pessoais, os valores, as aspirações, as razões e as conquistas presentes na dimensão humana do coaching e que contribuem na formação pessoal dos jovens atletas. Woods (2006) complementa esta questão ao dizer que:

\footnotetext{
${ }^{1}$ Utilizaremos a sigla T para Técnico e a numeração para a instituição em que trabalham. Assim T3 refere-se ao técnico entrevistado da terceira instituição. Quando ocorrer uma letra à direita do número refere-se à ordenação numérica dos técnicos da mesma instituição. Exemplo T29A: primeiro técnico da instituição 29.
} 
Coaches often help young people mature, set priorities, establish goals, learn sport skills, develop self-discipline, and so on. Because coaches typically work with younger athletes who are going through critical stages of personal development, they have a golden opportunity to influence young people (p. 312).

A prática esportiva competitiva requer muita disciplina e responsabilidade e, à medida que 0 nível de prática se eleva, estes aspectos se tornam essenciais, tais como: cuidados com a alimentação, tempo de repouso e sono, cumprimento de horários, entre outros. Na opinião de muitos técnicos, as demandas da GA e o seu caráter disciplinador influenciam, em grande medida, o estereótipo dos atletas competitivos da modalidade.

A educação formal também foi mencionada pelos técnicos e estes percebem que o ginásio e a escola se complementam na formação das crianças e dos jovens. De acordo com Werner (1994), a ginástica contribui para o desenvolvimento das capacidades cognitivas nas áreas de resolução de problemas, concepções artísticas/estéticas e propicia o conhecimento acerca do funcionamento do corpo. Esses aspectos, somados a disciplina e a responsabilidade que 0 esporte propicia, contribuem e facilitam o aprendizado escolar.

O prazer e a satisfação na prática esportiva também foram enfatizados pelos técnicos na sua filosofia de trabalho. É interessante observar a preocupação deles para que 0 processo de treinamento não seja "um sofrimento" (T8) ou algo imposto, mas que seja opção da criança e que esta participe por vontade própria e pelo prazer, visando à satisfação pessoal e não para atender aos interesses e anseios de outros. Porém, fica a dúvida se em meio a pressões e cobranças, os técnicos são capazes de primar por este aspecto, ou seja, de posicionar a criança e o jovem no centro desse processo de formação esportiva (BENTO, 1989).

O vínculo social e afetivo que se estabelece no ginásio também foi mencionado pelos sujeitos na sua filosofia de trabalho. Conforme o relato de muitos sujeitos, o ginásio é como uma família e, muitas vezes, os laços são mais fortes do que com os companheiros da escola ou parentes. Os técnicos citam que o estímulo da amizade e do companheirismo entre as crianças desenvolve valores humanos importantes para seu convívio na sociedade em geral e, por isso, estão inseridos na sua filosofia de trabalho. Essa visão coincide com os objetivos do Esporte no seu primórdio (DOUGE, 1999).

Sweeney (1975) já ressaltava as contribuições importantes da GA para os aspectos sócioafetivos, pois o ginasta depende e confia no seu treinador e nos companheiros de treino, pois a todo o momento recebe auxílio, é objeto de avaliação e é estimulado numa intensa interação social. Ademais, os ginastas aprendem a respeitar as particularidades dos seus pares, como os diferentes níveis de performance e de habilidades (WERNER, 1994).

Uma consideração importante de dois técnicos (T2 e T26) é a de não desvalorizar ou descartar o que a criança traz de casa ou de suas experiências e eles procuram eliminar "o que é ruim", mas que valorizam a individualidade: "cada um forma a sua ... a sua cartilha" (T26). Acreditamos que os técnicos tendem a respeitar, também, os valores, os princípios, o ritmo e as limitações das crianças, pois estes são influenciados pela história de vida dos indivíduos. Isso demonstra que a filosofia do técnico deve ser flexível. De acordo com Cassidy, Jones e Potrac (2004), embora a filosofia de trabalho do técnico seja baseada em princípios, ela deve ser flexível o bastante para considerar os fatores que permeiam a prática. Podemos incluir nesse contexto a filosofia de vida dos seus praticantes, suas características psicológicas e motoras, entre outros aspectos.

Assim como a filosofia de vida muda com o passar dos anos, a filosofia de trabalho também passa por mudanças que, de acordo com Kidman e Hanharan (2004), é modelada pelas experiências que ocorrem ao longo do exercício profissional e pelos conhecimentos que são adquiridos neste processo. A importância desses aspectos que alteram a filosofia de trabalho aparece no discurso de Martens (2004) que acredita que os técnicos de sucesso são aqueles que podem aprender novas técnicas, que são flexíveis o suficiente para mudar suas antigas formas de agir quando uma mudança é necessária, que aceitam críticas construtivas e que, de maneira crítica, podem se autoavaliar.

\section{Categoria masculina}

As categorias temáticas do setor masculino coincidem com aquelas do feminino, e revelam certa uniformidade dos depoimentos no tema em questão. 
Tabela 2. Síntese dos resultados do setor masculino.

\begin{tabular}{|c|c|c|}
\hline Categoria & Subcategoria & Unidades de registro \\
\hline \multirow[t]{2}{*}{ Educação } & $\begin{array}{l}\text { Formação } \\
\text { pessoal }\end{array}$ & $\begin{array}{l}\text { T1, T8, T10: "dar um bom exemplo"; "sobre disciplina, respeito"; "formação } \\
\text { geral da pessoa, do caráter". } \\
\text { T2: "ir até o seu limite e ele saber onde é o limite dele"; "respeitar a vontade } \\
\text { dele"; } \\
\text { T3: "personalidade da pessoa e pra autoestima"; "ter muita autoconfiança, } \\
\text { muita personalidade"; "Muita segurança, concentração"; "esforçado e que } \\
\text { gosta de superar desafio". } \\
\text { T12: "a motivação intrínseca, tentando se auto superar"; } \\
\text { T14, T21: "assiduidade, freqüência no treinamento, busca pelo } \\
\text { desenvolvimento da ginástica, essa ambição, coisa que imita a vida"; } \\
\text { "disciplina". } \\
\text { T25: "então eu valorizo o eu"; "se ele está inseguro eu não exijo". }\end{array}$ \\
\hline & $\begin{array}{l}\text { Educação } \\
\text { formal }\end{array}$ & $\begin{array}{l}\text { T2: "Eles fazem inglês antes do treino"; "valorização da educação"; "eu vou } \\
\text { ter a minha vida inteira para estudar, a Ginástica é passageira"; "ele pode } \\
\text { fazer as duas coisas juntas". } \\
\text { T8: "possível solucionar seu problema de estudo". }\end{array}$ \\
\hline \multicolumn{2}{|c|}{$\begin{array}{l}\text { Prazer, gosto pelo esporte, } \\
\text { satisfação pessoal }\end{array}$} & $\begin{array}{l}\text { T2: "faça aquilo que você gosta"; "Ele treina porque gosta" } \\
\text { T8: "satisfação pessoal"; "você faz ginástica para você". }\end{array}$ \\
\hline \multicolumn{2}{|c|}{$\begin{array}{l}\text { Incentivo financeiro e } \\
\text { assistencialismo }\end{array}$} & $\begin{array}{l}\text { T2: "Quando você tem um local que tem muitas pessoas de baixa renda, } \\
\text { isso vai influenciar. Se você tem dinheiro, você vai manter ele dentro do } \\
\text { Ginásio"; "eles estão movidos mais por interesses externos do que por } \\
\text { satisfação pessoal"; "Arrumamos a escola que deu bolsa para eles". } \\
\text { T15: "eu duvido que hoje que tinha grana ia treinar so porque gosta, se não } \\
\text { tivesse dinheiro" }\end{array}$ \\
\hline \multicolumn{2}{|c|}{ Saúde e formação física } & $\begin{array}{l}\text { T12: "esporte como um meio de saúde". } \\
\text { T24: "Alimentação". }\end{array}$ \\
\hline \multicolumn{2}{|c|}{ Fatores sócioafetivos } & $\begin{array}{l}\text { T14, T24, T25: "relacionamento com o grupo". } \\
\text { T15: "você não tem só respeito profissional você tem também o carinho } \\
\text { afetivo" } \\
\text { T21: "relação técnico com atleta, atleta com atleta". }\end{array}$ \\
\hline \multicolumn{2}{|c|}{ Exclusividade e abdicações } & $\begin{array}{l}\text { T2, T10, T24: "deixa de fazer muita coisa pelo esporte". } \\
\text { T3: "não tinham tempo para brincar". } \\
\text { T8: "a GA do ponto de vista de competição, é um esporte que exige muito } \\
\text { da pessoa levando a situações bastante estressantes ou de alto nível de } \\
\text { exigência". } \\
\text { T9: "Se saiu, ele que está saindo ou porque não conseguiu algum resultado } \\
\text { que esperava, ou por excesso de treinamento, ou está sentido falta de outra } \\
\text { coisa, dos amigos, da família, das festas, porque o esporte sempre prende } \\
\text { mais...". }\end{array}$ \\
\hline
\end{tabular}

A filosofia da maior parte dos técnicos da GAM está centrada na educação e abrange a formação pessoal, o respeito ao próximo, a disciplina, a perseverança, a coragem e a valorização do ser humano que são os aspectos apontados pelos próprios técnicos, como aqueles mais desenvolvidos no processo de instrução esportiva. A educação formal também é valorizada e deve ser equilibrada com o esporte.

Os fatores sócioafetivos relatados pelos técnicos na sua filosofia de trabalho se referem à amizade e ao vínculo de respeito mútuo entre eles e seus atletas. Isso confirma a posição de Lyle (2002) que cita que não há dúvidas de que os técnicos envolvidos no esporte de competição são conscientes da dimensão interpessoal do processo de instrução esportiva e que esta relação tem potencial para uma gama de efeitos positivos e negativos sobre o atleta. Por isso, a filosofia do treinador deve abranger os aspectos sócioafetivos que vise ao estabelecimento de um 
convívio harmonioso e, consequentemente, que potencialize o sucesso esportivo.

O prazer e a satisfação não foram tão enfatizados como no setor feminino, mas aqueles que o citaram percebem que a vontade própria e a sensação de realização são importantes na formação pessoal, conforme reforça Relvas (2005).

As novas categorias que emergiram com certa expressão foram: assistencialismo e exclusividade/abdicações. A primeira refere-se à melhoria das condições socioeconômicas que o esporte pode proporcionar através de bolsas de estudo e renda mensal. A segunda faz referência às privações que 0 envolvimento no esporte competitivo requer. Podemos elencar como exemplo, as restrições de tempo para atividades de lazer e de convívio social das crianças e dos jovens atletas. Percebemos certo pesar por parte dos técnicos, levando-nos a entender que o esporte é exigente e não há muita alternativa para aqueles que querem atingir o alto rendimento, ou seja, as abdicações de uma vida normal são quase que inevitáveis.

Cogan e Vidmar (2000) citam que muitos ginastas abdicam de suas atividades sociais para passar mais tempo no ginásio e centralizam a sua vida social no esporte interagindo apenas com seus técnicos e companheiros de treino. Porém, Woods (2006) enfatiza que compete ao técnico auxiliar os seus atletas a encontrarem um equilíbrio entre a sua dedicação ao esporte e as demais responsabilidades, seja com a sua família, amigos, escola e com o seu próprio bem estar. Podemos incluir, também, a participação dos pais nessa busca pelo equilíbrio das atividades. As palavras da ginasta americana Amanda Borden, medalhista olímpica e mundial, exemplificam a importância dessa questão:

I think balance is VERY important. I went to normal high school etc... Obviously I was very focused, but I had and have a life. If I wouldn't have made the Olympics, I still would've had my regular life. I never want to look back on my life and say I wish I would've (COGAN; VIDMAR 2000, p. 173).

Assim como na GAF, verificamos que "o treinador exerce uma influência muito pronunciada sobre as atitudes e os comportamentos, sobre os princípios, valores, orientações e sentidos de vida dos atletas" (BENTO 2006, p. 29), tanto dentro como fora do ginásio. $O$ que confirma a necessidade de uma filosofia de trabalho bem desenvolvida e que privilegie o indivíduo, o ser humano.

\section{Considerações finais}

Conforme levantamos no referencial teórico, a crítica sobre o esporte contemporâneo é de que o sistema está repleto de indivíduos que parecem ter perdido o sentido do valor humano, o respeito por outros e o significado de fair play. Alguns técnicos e atletas justificam seus comportamentos e estratégias pelas necessidades de manter os financiamentos e patrocínios, para ganhar reconhecimento e recompensas, se manter competitivo e, principalmente, vencer. E, esses e outros motivos, contribuem para que a abordagem do esporte passe a ser "ganhar a todo custo", independente do nível de prática (HAINES, 1989; LUMPKIN; CUNEEN, 2001; REYNOLDS, 2005).

No esporte, o comportamento individual é baseado nos valores, princípios e concepções pessoais. Desta forma, é importante que os técnicos questionem a si e aos seus atletas antes de estabelecerem sua filosofia de trabalho e que a compartilhe com os atletas, pais e com a instituição esportiva a qual está vinculado.

Ter uma base de princípios e valores no esporte se faz ainda mais necessário quando lidamos com crianças e jovens, pois é um momento crítico para receber estímulos do ambiente sendo a fase mais moldável do indivíduo (BEE, 1997; NEWCOMBE, 1999). A partir de então, há certas mudanças, mas a base de sua personalidade e condutas foi estabelecida nessas fases iniciais da vida.

Então, advém a importância dos técnicos da GA que lidam, especialmente, com crianças e jovens de fundamentarem sua filosofia de trabalho, conhecer a si próprio, seus valores e crenças e estar ciente das dificuldades e obstáculos que encontrarão a fim de estabelecer um pano de fundo para as suas ações (REYNOLDS, 2005).

Percebemos, em geral, certa insegurança dos técnicos quando no momento do questionamento sobre a filosofia de seu trabalho. Não queremos inferir que não o tivessem, mas acreditamos que muitos não chegaram a pensar sobre a filosofia do programa na mesma intensidade com que planejam as atividades de ensino. Não pensamos que seja descaso, mas a própria sociedade não valoriza este aspecto. Mesmo as instituições de 
ensino formal, as escolas, não raras vezes confundem a filosofia de trabalho com as abordagens de ensino ou objetivos do ensino ou em casos mais críticos, com as próprias disciplinas curriculares.

Ao longo da nossa formação profissional, poucas vezes somos incitados a refletir sobre nossos valores, princípios éticos e morais, opiniões, crenças e as influências de experiências anteriores que vivenciamos, as quais se configuram na base para o estabelecimento de nossa filosofia de trabalho (HAINES, 1989; REYNOLDS, 2005).

A partir dos dados levantados pudemos constatar que não há uma filosofia de trabalho consistente na maior parte dos ginásios consultados no estudo, pois em muitas instituições ela se confunde com os próprios objetivos do programa.

Provavelmente, durante a formação dos técnicos, pouco se discutiu a respeito da filosofia. Portanto, não podemos atribuir-lhes totalmente a culpa, mas incentivá-los a refletir e a mudar aqueles aspectos que julgarem necessários, quem sabe, a filosofia de trabalho e alguns valores éticos e morais. Mas, sem gerar conflitos com as instituições empregadoras, pois percebemos pelos relatos de que muitas destas não têm essa preocupação.

Independente da postura das instituições, os técnicos não devem perder o foco sobre as necessidades e os interesses dos praticantes e sobre seus valores e princípios. Este equilíbrio é importante para que suas ações não se percam em meio a tantos desvios que os objetivos do esporte podem seguir na sociedade atual.

Assim, em meio a tantos outros desafios que os nossos técnicos já enfrentam, lançamos mais este, ou seja, de estabelecer uma base filosófica de trabalho que harmonize com os interesses de todos aqueles que estão envolvidos neste cenário e que sempre seja em beneficio dos praticantes.

\section{Referências}

ARAÚJO, D. Para vencer a competição de valores. Treino Desportivo, Lisboa, n.6, ano VII, $3^{\mathrm{a}}$ série, p.60-65, 2005.

BARDIN, L. Análise de conteúdo. Lisboa: Edições 70, 2010.
BEE, H. O ciclo vital. Tradução Regina Garcez. Porto Alegre: Artes Médicas, 1997.

BENTO, J. O. A criança no treino e desporto de rendimento. In: Kinesis, Santa Maria, v.1, n.5, p. 9-35, 1989.

BENTO, J. O. Da pedagogia do desporto. In: TANI, G.; BENTO, J. O.; PETERSEN, R. D. de S. Pedagogia do Desporto. Rio de Janeiro: Guanabara Koogan, 2006.

BORNHEIM, G. A. Introdução ao filosofar. Rio de Janeiro: Globo, 2003.

CASSIDY, T.; JONES, R. L.; POTRAC, P. Understanding sports coaching: the social, cultural and pedagogical foundations of coaching practice. 2. Ed. Nova York: Routledge, 2009.

COELHO, O. Pedagogia do Desporto: contributos para uma compreensão do desporto juvenil. Lisboa: Horizonte de Cultura Física, 1988, p.78.

COGAN, K. D.; VIDMAR, P. Sport psychology library: gymnastics. Morgantown: Fitness Information Technology, 2000.

COMTE-SPONVILLE, A. Dicionário filosófico. São Paulo: Martins Fontes, 2003.

DOUGE, B. Progressão das Actividades não Competitivas para as Competitivas. Treino Desportivo, Lisboa, n.8, p.6-8, out/1999.

GONÇALVES, C. Um olhar sobre o processo de formação do jovem praticante. Treino Desportivo, Lisboa, n. 2, p.42-48, 1999. Edição especial.

HAINES, C. Coaching Certification Manual: Level 2 Men. Gymnastics Canada Gymnastique, Ontario, Canadá, 1989.

HAINES, C. Coaching Certification Manual:

Level 2 Women. Gymnastics Canada Gymnastique, Ontario, Canadá, 1989.

KIDMAN, L.; HANRAHAN, S. The coaching process: a practical guide to becoming an effective sports coach. 2. Ed. Wellington: Dunmore Publishing Limited, 2004.

LUMPKIN, A.; CUNEEN, J. Developing a Personal Philosophy of Sport. Journal of Physical

Education, Recreation, and Dance, Reston, v.72, n.8, p.40-43, 2001. 
LYLE, J. Sports coaching concepts: a

framework for coaches' behavior. Nova York:

Routledge, 2002.

MARTENS, R. Coaches guide to sport

psychology. Champaign: Human Kinetics, 1987.

MARTENS, R. Successful coaching. 3. Ed.

Champaign: Human Kinetics, 2004.

MCCALLISTER, S.G.; BLINDE, E.M; WEISS, W.M. Teaching Values and Implementing Philosophies: Dilemmas of the Youth Sport Coach. The Physical Educator, Indianapolis, v.57, n.1, p.35-44, 2000.

RELVAS, H. (Des) ajustes entre treinadores e jovens atletas nos motivos para a prática desportiva. Treino Desportivo, Lisboa, n.27, p.47, 2005.

REYNOLDS, F. Developing a formal coaching philosophy. Coaches Report, Canberra, v.12, n.2, p.10-12, 2005.

SALGADO, M. Para nós, jovens treinadores. Treino Desportivo, Lisboa, Especial 2, p.67-71, Novembro, 1999.

SARMENTO, P. A função pedagógica do treinador: uma abordagem comportamental.

Treino Desportivo, Lisboa, especial, n.6, ano VII, $3^{\mathrm{a}}$. série, novembro, p.46-51, 2005.

SEKINE, M.; HATA, T. The crisis of Modern Sport and the Dimension of Achievement for its Conquest. International Journal of Sport and Health Science, Tokyo, v.180, p.180-186, 2004.

SMOLEUSKIY, V.; GAVERDOUSKIY, I. Tratado general de gimnasia artística deportiva.

Barcelona: Paidotribo, 1996.

SWEENEY, J. Ginástica Olímpica. Sao PauloRio de Janeiro: Difel, 1975.

TAYLOR, J.; WILSON, G. S. Applying sport psychology: four perspectives. Champaign: Human Kinetics, 2005.

TRIVIÑOS, A. N. S. Introdução à Pesquisa em Ciências Sociais: a pesquisa qualitativa em educação. São Paulo: Atlas, 1987.

WERNER, P. H. Teaching children gymnastics: becoming a master teacher. Champaign: Human Kinetics, 1994.

WILCOX, S.;TRUDEL, P. Constructing the coaching principles and beliefs of a youth ice hockey coach. Avante, n. 4, v.3, p. 39-66, 1998.
WOODS, R. Social issues in sport. Champaign: Human Kinetics, 2007.

\section{Endereço:}

Myrian Nunomura

Rua Antonio Eduardo Barbosa de Andrade, 180 Jardim Nova Aliança.

Ribeirão Preto SP Brasil.

14026-556

e-mail:mnunomur@usp.br

Recebido em: 28 de janeiro de 2011.

Aceito em: 13 de outubro de 2012.

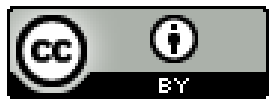

Motriz. Revista de Educação Física. UNESP, Rio Claro, SP, Brasil - elSSN: 1980-6574 - está licenciada sob Creative Commons - Atribuicão 3.0 